\title{
A Japanese infant presenting with hypocalcemic seizures resulting from hypovitaminosis $D$ induced by non-celiac gluten sensitivity
}

\author{
Nobuyuki Kawano ${ }^{1}$, Tomoyo Itonaga ${ }^{1}$, Manabu Tojigamori ${ }^{2}$, Tsutomu Daa ${ }^{3}$, and Kenji Ihara ${ }^{1}$ \\ ${ }^{1}$ Department of Pediatrics, Oita University Faculty of Medicine, Oita, Japan \\ ${ }^{2}$ Department of Gastroenterological and Pediatric Surgery, Oita University Faculty of Medicine, Oita, Japan \\ ${ }^{3}$ Department of Diagnostic Pathology, Oita University Faculty of Medicine, Oita, Japan
}

\begin{abstract}
Vitamin D deficiency is a major cause of hypocalcemic seizures in infants. Chronic enteropathy can cause both malnutrition and vitamin deficiency disorders, such as celiac disease, in Western Caucasians. However, gluten-related disorders are considered uncommon in most Asian countries, and there have been no reports of any infant being diagnosed with a gluten-related disorder in Japan. Here, we describe a case where a Japanese infant, with non-celiac gluten sensitivity, presented with hypocalcemic seizures resulting from a vitamin D deficiency. In this case, an eight-month-old boy had an afebrile seizure, and blood tests revealed both hypocalcemia and prolonged prothrombin time resulting in his transfer to our hospital. The presence of fatty stools and evidence of multiple vitamin deficiencies indicated some form of fat malabsorption. His laboratory and histological findings showed enteropathy, and he was thus diagnosed with non-celiac gluten sensitivity. Therefore, he was treated with a gluten-free diet supplemented with vitamins. This case suggests that infants with a vitamin $\mathrm{D}$ deficiency caused by celiac disease or non-celiac gluten sensitivity should be carefully monitored when they are given oral supplements of vitamin D, to prevent any adverse side-effects associated with the varied roles of vitamin $\mathrm{D}$ in the immune response.
\end{abstract}

Key words: hypocalcemia, celiac disease, anti-gliadin antibody, gluten-related disorders, non-celiac gluten sensitivity

\section{Introduction}

Vitamin D deficiency is recognized as a major cause of hypocalcemic seizures in infants. Factors contributing to vitamin $\mathrm{D}$ deficiency include a restricted or unbalanced diet and insufficient sun exposure. Cholestasis due to biliary atresia, citrin deficiency, and inborn errors of bile acid metabolism have been reported as minor causes $(1,2)$. Chronic enteropathy may be responsible for multiple vitamin deficiencies resulting from malabsorption. While gluten-sensitive enteropathy, that is, celiac disease (CD), is considered very rare in many Asian countries, there is evidence of increasing CD incidence in Asia, as traditional rice-based diets are gradually being replaced by Western-style diets with higher wheat products/content, including gluten. The seroprevalence and prevalence of CD in Asia were 1.6\% and $0.5 \%$, respectively based on the study of systematic review and meta-analysis in 2016 (3).
Gluten is a general name given to the proteins that are formally known as prolamins and are contained in grains such as wheat, rye, and barley. Gluten can be further classified based on the specific grains in which they are found with glutenin and gliadin making up the prolamins content in wheat, while secalin and hordeins are found in rye and barley, respectively. Gluten proteins are characterized by their high proline and glutamine content which facilitate their resistance to several proteolytic enzymes in the gastrointestinal tract. Incomplete digestion of gluten leads to significant changes in the gut and when these peptides cross the epithelial barrier, extra-intestinal symptoms may be induced following immune activation, resulting in the more severe phenotypes associated with gluten-related disorders (4).

Gluten-related disorders are generally divided into three categories: the above-mentioned CD, wheat allergy (WA), and non-celiac gluten sensitivity (NCGS). The

Received: December 2, 2020 Accepted: January 10, 2021

Corresponding author: Kenji Ihara, M.D., Ph.D., Department of Pediatrics, Oita University Faculty of Medicine, 1-1 Idaigaoka, Yufu, Oita 879-5593, Japan

E-mail: k-ihara@oita-u.ac.jp 
clinical manifestations of these disorders are similar, and their most common clinical manifestations include abdominal pain, bloating, and/or changes in bowel patterns, although some patients may complain of extraintestinal symptoms. Diagnosis of both CD and WA is based on a combination of findings from the patient's clinical history and specific tests, including serology and duodenal biopsies for CD or laboratory and functional assays for WA. NCGS is primarily a diagnosis of exclusion reached when there is no specific serological or histological evidence of CD and the absence of any clear-cut diagnostic criteria or specific biomarkers $(5,6)$.

Here we describe a case involving a Japanese infant with NCGS who experienced remarkable lipid deficiency that presented as hypocalcemic seizures resulting from vitamin $\mathrm{D}$ deficiency.

\section{Case Report}

This male patient was born at $39 \mathrm{wk}$ and $1 \mathrm{~d}$ of gestation as the first child of healthy Japanese parents. His birth weight was $3,708 \mathrm{~g}$, and his height was $48.7 \mathrm{~cm}$. He was exclusively breast-fed from birth with baby foods, such as rice paste or grated vegetables, introduced from 5 mo of age. However, his food intake was insufficient, and he presented with a strong preference for bread over other food products. He then developed persistent diarrhea with muddy stools with failure to thrive, not reaching weight milestones for several months. At eight months of age, he presented with a systemic tonic-clonic seizure and was transferred to the pediatric clinic of the regional emergency center.

Upon arrival, the seizures were shown to be transient and a blood test showed that the patient was experiencing hypocalcemia $(4.9 \mathrm{mg} / \mathrm{dL}$, [ionized Ca, 0.745 $\mathrm{mmol} / \mathrm{L}]$ ) with a prolonged prothrombin time (PT; PTINR, 7.8) (Table 1). After primary treatment for the seizure, the patient was immediately transferred to our hospital. At intake he was awakened, and a physical examination revealed no neurological abnormalities. His height was $64.3 \mathrm{~cm}$ (-2.0 standard deviations [SD]), and his weight was $6.3 \mathrm{~kg}$ (Kaup index 15.2). He had been failing to thrive from five months of age, as shown by his growth chart (Fig. 1).

In addition to the hypocalcemia, which was confirmed in the laboratory data received from the previous hospital, this patient also presented with several unusual findings including a coagulation abnormality with prolonged PT and APTT, hypolipidemia, and low levels of vitamin A, D, E, and K, suggesting severe malabsorption. Sudan staining also revealed excess lipid droplets in the stool (Table 1). Wrist X-ray showed cupping of the distal radius and flaring of the distal ulna, indicating severe rickets (Fig. 2). Serum biochemical analysis and abdominal computed tomography demonstrated no findings suggesting reduced bile salt synthesis or secretion, such as biliary atresia or cystic fibrosis, congenital apolipoprotein abnormalities, or intestinal lymphangiectasia.
Given these results he was diagnosed with multiple vitamin malabsorption resulting in severe hypocalcemia presenting as seizures and rickets due to vitamin D deficiency, a subclinical vitamin $\mathrm{K}$ deficiency and hypolipidemia, all of which resulted in a failure to thrive. No metabolic diseases or malformations of the hepatobiliary tract that might cause cholestasis were identified at that time. Intravenous supplementation of calcium gluconate followed by alpha calcidol, calcium lactate tocopherol acetic acid, and menatetrenone were started, but his chronic diarrhea with muddy stools continued over several days (Fig. 3).

We then went on to perform an esophagogastroduodenoscopy and a duodenal biopsy. Non-specific findings of chronic inflammation in the small intestine and villous atrophy were noted (Fig. 4) and several antigen-specific IgEs were detected, with positive results from class 0 to class 3 , although the symptoms of the patient were not suggestive of rapid onset WA. The total immunoglobulin levels for IgG, IgA, and IgM were 764, 64, and $70 \mathrm{mg} / \mathrm{dL}$, respectively. Antigen-specific antibodies were negative for antitissue transglutaminase (tTG) IgA antibodies but antideamidated gliadin peptides (DGP) antibodies were detected in these samples (anti-DGP-IgG antibody > 100 EU, anti-DGP-IgA antibody 84 EU). The patient was shown to harbor HLA subtypes DQ4 and DQ7, neither of which are associated with a predisposition to CD in Caucasians (DQ2/DQ8). Based on the new 2020 guidelines for the diagnosis of pediatric coeliac disease provided by the European Society for Pediatric Gastroenterology Hepatology and Nutrition (ESPGHAN) (7), we did not diagnose CD, given the negative anti-TGAIgA antibody test in the sera and the normal IgA levels in the patient. However, given the clinical manifestations and histopathological findings of enteropathy we were able to diagnose this patient with NCSD.

After the NCSD diagnosis, at nine months of age, i.e. one month after admission, we initiated a gluten-free diet. His body weight then slowly began to increase and the serum levels of the fat-soluble vitamins gradually improved and reached normal ranges within 5 mo of onset (i.e. 13 mo of age). At $16 \mathrm{mo}$ of age (8 mo after onset), his height and weight were $71.0 \mathrm{~cm}$ and $8.0 \mathrm{~kg}$, respectively and at that time, all anti-DGP antibodies were shown to be below the level of detection. At $22 \mathrm{mo}$ of age, the serum calcium, phosphate, and ALP levels were all normalized despite low calcium excretion in the urine even under supplementation with vitamins and calcium lactate, suggesting that the malabsorption of the calcium and vitamins persisted.

\section{Discussion}

To the best of our knowledge, this is the first report of a Japanese infant diagnosed with NCGS presenting with severe multiple vitamin deficiency, fat malabsorption and hypolipidemia. NCGS is a novel condition defined by symptoms similar to those of CD 
Table 1. Laboratory data

\begin{tabular}{|c|c|c|c|}
\hline $\begin{array}{l}\text { Blood count } \\
\text { White blood cell } \\
\text { Platelet }\end{array}$ & $\begin{array}{r}14,140 / \mu \mathrm{L} \\
40.3 \times 10^{4} / \mu \mathrm{L}\end{array}$ & $\mathrm{Hb}$ & $11.6 \mathrm{~g} / \mathrm{dL}$ \\
\hline \multicolumn{4}{|l|}{ Serum parameters } \\
\hline Total protein & $6.3 \mathrm{~g} / \mathrm{dL}$ & Albumin & $4.6 \mathrm{~g} / \mathrm{dL}$ \\
\hline Cholesterol & $67 \mathrm{mg} / \mathrm{dL}$ & $\mathrm{Na}$ & $136 \mathrm{mEq} / \mathrm{L}$ \\
\hline $\mathrm{K}$ & $3.4 \mathrm{mEq} / \mathrm{L}$ & $\mathrm{Cl}$ & $104 \mathrm{mEq} / \mathrm{L}$ \\
\hline $\mathrm{Ca}$ & $4.9 \mathrm{mg} / \mathrm{dL}$ & $\mathrm{P}$ & $2.2 \mathrm{mg} / \mathrm{dL}$ \\
\hline $\mathrm{Mg}$ & $1.5 \mathrm{mg} / \mathrm{dL}$ & $\mathrm{Cu}$ & $70.1 \mathrm{mg} / \mathrm{dL}$ \\
\hline Ionized $\mathrm{Ca}$ & $0.745 \mathrm{mmol} / \mathrm{L}$ & ALP & $4,722 \mathrm{U} / \mathrm{L}$ \\
\hline Total bilirubin & $0.41 \mathrm{mg} / \mathrm{dL}$ & Amylase & $30 \mathrm{U} / \mathrm{L}$ \\
\hline Pancreatic amylase & $5 \mathrm{U} / \mathrm{L}$ & Esterase 1 & $134.5 \mathrm{ng} / \mathrm{dL}$ \\
\hline Trypsin & $747 \mathrm{ng} / \mathrm{mL}$ & Lipase & $12 \mathrm{U} / \mathrm{L}$ \\
\hline \multicolumn{4}{|l|}{ Coagulation markers } \\
\hline PT-INR & 7.8 & APTT & $32.7 \%$ \\
\hline \multicolumn{4}{|l|}{ Vitamins } \\
\hline Vitamin A & $11 \mathrm{U} / \mathrm{dL}$ & Vitamin E & $0.25 \mathrm{mg} / \mathrm{dL}$ \\
\hline 25(OH)-Vitamin D & $<4.0 \mathrm{ng} / \mathrm{mL}$ & PIVKA-II & $>75,000 \mathrm{mAU} / \mathrm{mL}$ \\
\hline intact PTH & $372 \mathrm{pg} / \mathrm{mL}$ & $1,25(\mathrm{OH})_{2}$-Vitamin D & $28 \mathrm{pg} / \mathrm{mL}$ \\
\hline Urine & & Stool test & \\
\hline $\mathrm{Ca} / \mathrm{Cr}$ ratio & 0.04 & Sudan staining & Positive \\
\hline$\% \mathrm{TRP}$ & N/A & & \\
\hline \multicolumn{4}{|l|}{ Lipoprotein fraction } \\
\hline Alpha & $36.7 \%$ & (Standard range: 26.9-50.5) & \\
\hline Pre-beta & $15.9 \%$ & (Standard range: 7.9-23.8) & \\
\hline Beta & $39.6 \%$ & (Standard range: $33.3-55.5)$ & \\
\hline \multicolumn{4}{|l|}{ Allergy test } \\
\hline Total IgE & $62 \mathrm{IU} / \mathrm{mL}$ & (Standard range: 8-56) & \\
\hline [Immunoassays for allergen-specific IgE] & & & \\
\hline Milk & $4.19 \mathrm{IU} / \mathrm{mL}$ & Class 3 & \\
\hline Wheat & $1.18 \mathrm{IU} / \mathrm{mL}$ & Class 2 & \\
\hline Gluten & $1.27 \mathrm{IU} / \mathrm{mL}$ & Class 2 & \\
\hline$\omega-5$ gliadin & $<0.10 \mathrm{IU} / \mathrm{mL}$ & Class 0 & \\
\hline Rye & $0.55 \mathrm{IU} / \mathrm{mL}$ & Class 1 & \\
\hline \multicolumn{4}{|l|}{ Autoantibody } \\
\hline Anti tTG-IgA & $<1 \mathrm{U} / \mathrm{mL}$ & (Standard value: < 10) & \\
\hline Anti DGP-IgG & $>100 \mathrm{U}$ & (Standard value: $<20)$ & \\
\hline Anti DGP-IgA & $84 \mathrm{U}$ & (Standard value: <20) & \\
\hline \multicolumn{4}{|l|}{ HLA genotyping } \\
\hline DQ4 & $(\mathrm{DQB} 1 * 04: 01)$ & DQ7 & $(\mathrm{DQB} 1 * 03: 01)$ \\
\hline
\end{tabular}

tTG, tissue transglutaminase; DGP, deamidated gliadin peptide. N/A, not assessed.

that disappear after the withdrawal of gluten without the specific antibody or histological findings associated with SD (6). The negative findings related to serum protein loss/deficiency, serum electrolytic imbalance and dehydration were also suggestive of NCGS and unlikely to indicate infantile enteropathy induced by a viral infection or congenital lymphangiectasia.

Fat malabsorption can be caused by disturbances in any of the following steps of fat assimilation: 1, fatty acids stimulate cholecystokinin (CCK) release from the small intestine and upper jejunum, and this stimulates the release of amylase or lipase from the pancreas, resulting in gallbladder contraction inducing the release of bile into the intestine; 2 , bile acids and salts combine with dietary fat to form mixed micelles (fat solubilization); 3, pancreatic lipase cleaves long-chain triglycerides, yielding fatty acids and monoglycerides; 4, mixed micelles diffuse to the brush border of the enterocytes; 5, fatty acids are re-esterified to form triglycerides within the enterocyte, and triglycerides combine with cholesterol ester, fat-soluble vitamins, phospholipids, and apoproteins to form chylomicrons; 6 , chylomicrons leave the enterocytes via exocytosis, enter the mesenteric lymphatics, pass into the thoracic duct, 


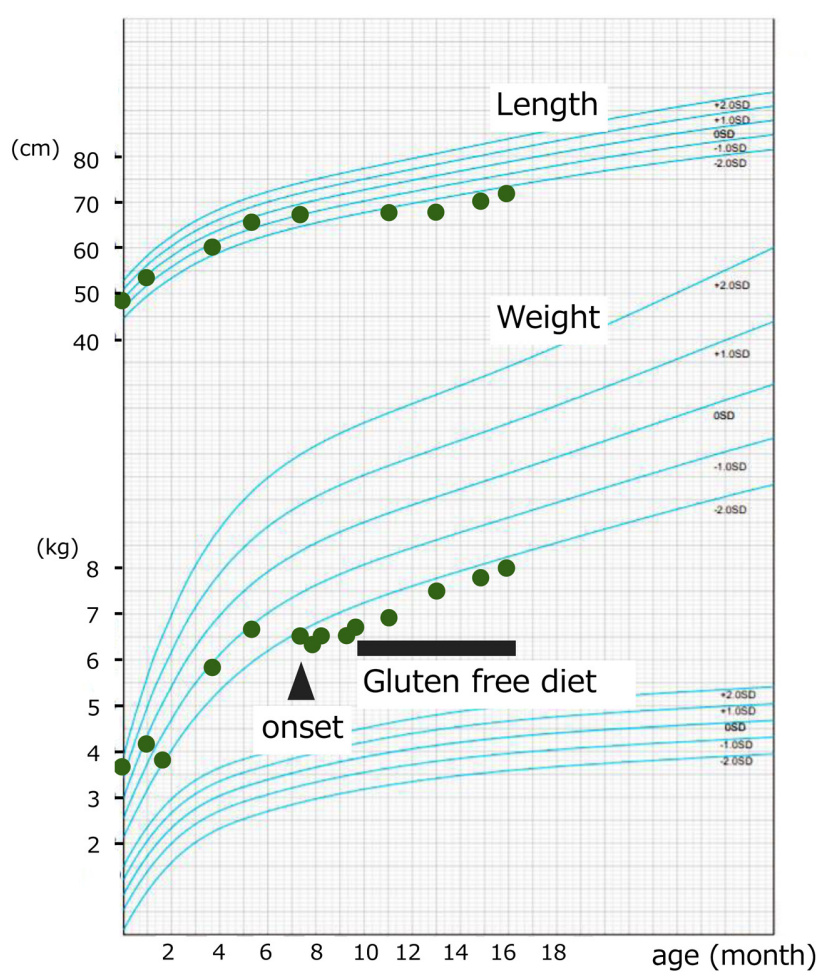

Fig. 1. Growth curve of the patient. The closed triangles indicate the onset of clinical symptoms. The horizontal bar shows the start of the treatment using a gluten-free diet.

and reach the circulatory system (8). The epithelial cells of the villi regulate absorption of salt and water and when the cells at the tip of the villus are damaged, the salt and water content of the intestinal lumen increases, decreasing bile salts concentration, and reducing fat and bile acid production. In addition, the endocrine cells in the proximal small intestine that release CCK may become dysfunctional or atrophic resulting in a failure in CCK-stimulated digestive enzyme release and fat solubilization in the luminal layer (steps 1 and 2). These types of defects are thought to result in a more severe malabsorption of lipids with less impact on other nutrients (9). Low plasma levels of calcium, iron, selenium, magnesium, zinc, niacin, thiamine, riboflavin, and vitamins $A$ and $D$, were found in several $C D$ patients when they were ingesting a gluten-free diet (10) and children with CD have lower levels of vitamins A or D when compared with healthy children (11). Although the vitamin levels of infants with CD and NCGS have not been reported because of the rarity of these conditions, even in Western countries, our experience with this patient indicates that severe vitamin deficiency can occur even in infants with NCGS who have an extreme preference for wheat-containing foods, such as bread.

Vitamin D plays a major role in the maintenance of the skeleton. Biologically active vitamin D enhances calcium absorption by regulating calcium transport in the small intestine, promoting the bone growth associated with collagen matrix mineralization. Vitamin D is also

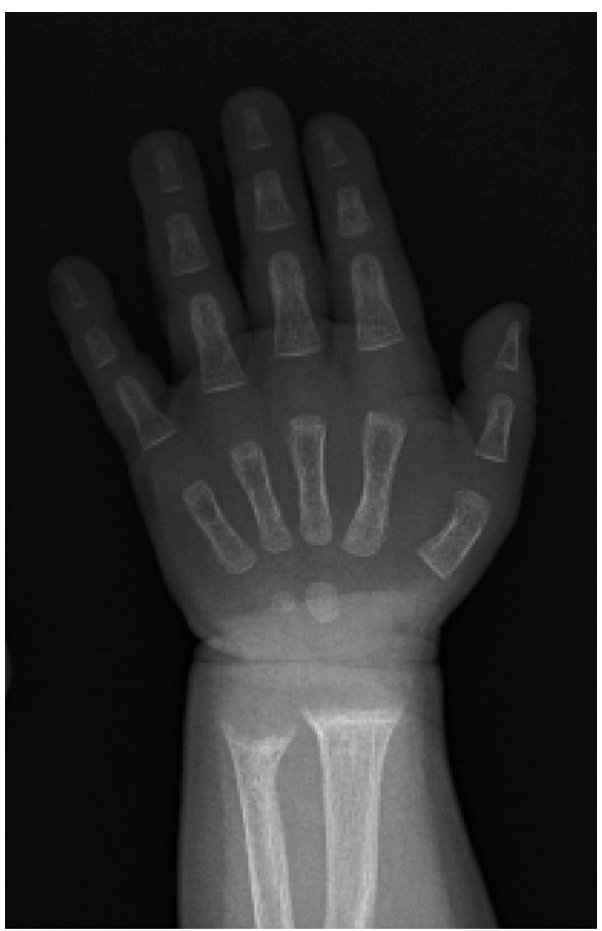

Fig. 2. X-ray image of the left hand at admission (8 mo of age). The image shows cupping and fraying of the metaphysis.

known to serve some function in the immune modulation of both the innate and adaptive immune responses. Therefore, vitamin D deficiency plays a critical role in CD development serving to support the dysregulation of the immune response in the intestinal mucosa which ultimately results in an increased susceptibility to acute gastrointestinal infection (12). Alternatively, large doses of oral vitamin D might upregulate the expression of various cytokines, chemokines, and Toll-like receptors increasing the risk of inducing CD in genetically predisposed individuals (13). Therefore, careful observation of CD or NCGS patients is necessary when they are receiving oral vitamin $\mathrm{D}$ supplementation to treat their vitamin $\mathrm{D}$ deficiency.

Most patients with CD or NCSD follow a chronic course, with variable clinical manifestations, although some CD patients do experience rapid and severe disease onset called "celiac crisis", which presents with severe dehydration, renal dysfunction, metabolic acidosis, neurological symptoms, hypoproteinemia, electrolyte abnormalities, and rapid weight loss. Infant patients might be at a much higher risk of a celiac crisis than adults because undiagnosed infants can be unintentionally exposed to gluten-containing foods (14). To avoid such a crisis, we should consider gluten-related disorders as the differential diagnosis for chronic diarrhea associated with dehydration, electrolyte abnormalities, weight loss, and lipid malabsorption.

In conclusion, severe lipid malabsorption with chronic diarrhea during the weaning period may be a key manifestation of gluten-related disorders during infancy. 


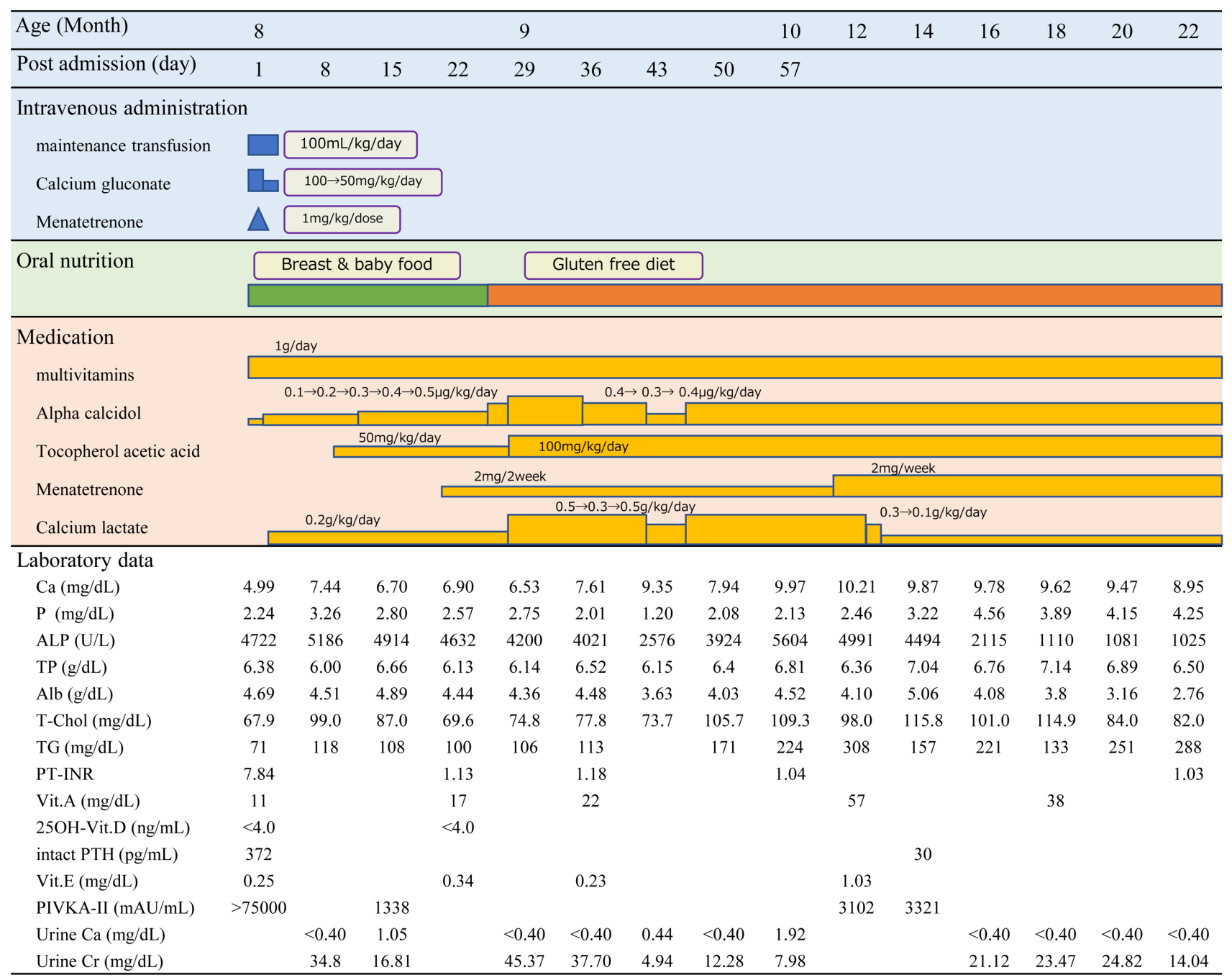

Fig. 3. Clinical course of the patient. The primary and follow-up treatments and their key laboratory findings are serially described.

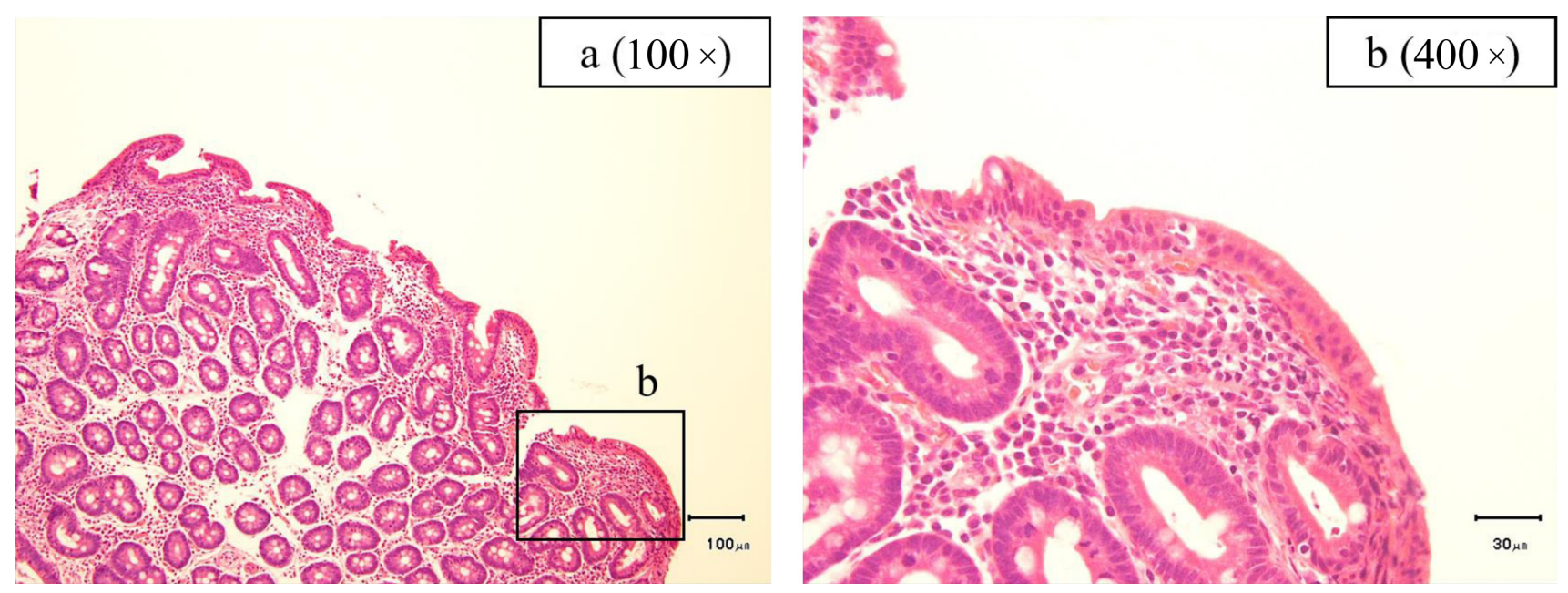

Fig. 4. Histopathological findings of the duodenal biopsies (H\&E staining). The patient's condition was categorized as type $3 \mathrm{c}$ based on the modified Marsh classification. a $(100 \times)$ : Flat mucosa with complete loss of the normal villous architecture. b $(400 \times)$ : Increased intraepithelial lymphocyte infiltration. 
The measurement of antigen-specific antibodies in the serum should be considered for patients presenting with fat malabsorption, even in historically low-risk groups such as Japanese infants. Careful observation is needed for infants with CD or NCGS who are undergoing oral vitamin $\mathrm{D}$ supplementation to prevent any unwanted side-effects associated with the varied roles of vitamin $\mathrm{D}$ in immune modulation.

\section{Compliance with ethical standards}

Human rights: All procedures were performed in accordance with the ethical standards laid out in the
1964 Declaration of Helsinki and its later amendments.

Informed consent: Informed consent was obtained from the patient's parents for inclusion in the study.

Conflict of interests: The authors have no conflicts of interest to declare.

\section{Acknowledgements}

We thank Dr. Brian Quinn for his support and assistance when preparing the manuscript.

\section{References}

1. Kubota T, Kotani T, Miyoshi Y, Santo Y, Hirai H, Namba N, et al. A spectrum of clinical presentations in seven Japanese patients with vitamin D deficiency. Clin Pediatr Endocrinol 2006;15: 23-8. [Medline] [CrossRef]

2. Omotobara-Yabe T, Kuga S, Takeguchi M, Ihara K. Vitamin D deficiency associated with dilated cardiomyopathy in early infancy caused by maternal cholestasis. Clin Pediatr Endocrinol 2018;27: 187-92. [Medline] [CrossRef]

3. Singh P, Arora S, Singh A, Strand TA, Makharia GK. Prevalence of celiac disease in Asia: A systematic review and metaanalysis. J Gastroenterol Hepatol 2016;31: 1095-101. [Medline] [CrossRef]

4. Sapone A, Bai JC, Ciacci C, Dolinsek J, Green PH, Hadjivassiliou M, et al. Spectrum of gluten-related disorders: consensus on new nomenclature and classification. BMC Med 2012;10: 13. [Medline] [CrossRef]

5. Igbinedion SO, Ansari J, Vasikaran A, Gavins FN, Jordan P, Boktor M, et al. Non-celiac gluten sensitivity: All wheat attack is not celiac. World J Gastroenterol 2017;23: 7201-10. [Medline] [CrossRef]

6. Roszkowska A, Pawlicka M, Mroczek A, Bałabuszek K, Nieradko-Iwanicka B. Non-celiac gluten sensitivity: a review. Medicina (Kaunas) 2019;55: E222. [Medline] [CrossRef]

7. Husby S, Koletzko S, Korponay-Szabó I, Kurppa K, Mearin ML, Ribes-Koninckx C, et al. European Society Paediatric Gastroenterology, Hepatology and Nutrition guidelines for diagnosing coeliac disease 2020. J Pediatr Gastroenterol Nutr 2020;70: 141-56. [Medline] [CrossRef]

8. Wang HH, Liu M, Li X, Portincasa P, Wang DQ. Impaired intestinal cholecystokinin secretion, a fascinating but overlooked link between coeliac disease and cholesterol gallstone disease. Eur J Clin Invest 2017;47: 328-33. [Medline] [CrossRef]

9. Wouthuyzen-Bakker M, Bodewes FA, Verkade HJ. Persistent fat malabsorption in cystic fibrosis; lessons from patients and mice. J Cyst Fibros 2011;10: 150-8. [Medline] [CrossRef]

10. Rubio-Tapia A, Hill ID, Kelly CP, Calderwood AH, Murray JA, American College of Gastroenterology. ACG clinical guidelines: diagnosis and management of celiac disease. Am J Gastroenterol 2013;108: 656-76, quiz 677. [Medline] [CrossRef]

11. Sentongo TA, Semaeo EJ, Stettler N, Piccoli DA, Stallings VA, Zemel BS. Vitamin D status in children, adolescents, and young adults with Crohn disease. Am J Clin Nutr 2002;76: 1077-81. [Medline] [CrossRef]

12. Wu D, Lewis ED, Pae M, Meydani SN. Nutritional modulation of immune function: analysis of evidence, mechanisms, and clinical relevance. Front Immunol 2019;9: 3160. [Medline] [CrossRef]

13. Bittker SS. Elevated levels of 1,25-dihydroxyvitamin D in plasma as a missing risk factor for celiac disease. Clin Exp Gastroenterol 2020;13: 1-15. [Medline] [CrossRef]

14. Balaban DV, Dima A, Jurcut C, Popp A, Jinga M. Celiac crisis, a rare occurrence in adult celiac disease: A systematic review. World J Clin Cases 2019;7: 311-9. [Medline] [CrossRef] 